\title{
Prognostic value of estrogen receptor in WHO Grade III meningioma: a long-term follow-up study from a single institution
}

\author{
*Lingyang Hua, MD, ${ }^{1}$ Hongda Zhu, MD, ${ }^{1}$ Jingrun Li, MD, ${ }^{1}$ Hailiang Tang, MD, ${ }^{1}$ Dapeng Kuang, MD, ${ }^{2}$ \\ Yin Wang, MD, ${ }^{3}$ Feng Tang, MD, ${ }^{4}$ Xiancheng Chen, MD, ${ }^{1}$ Liangfu Zhou, MD, ${ }^{1}$ Qing Xie, MD, ${ }^{1}$ and \\ Ye Gong, MD ${ }^{1,2}$
}

Departments of ${ }^{1}$ Neurosurgery, ${ }^{2}$ Critical Care Medicine, ${ }^{3}$ Neuropathology, and ${ }^{4}$ Pathology, Huashan Hospital, Shanghai Medical College, Fudan University, Shanghai, China

\begin{abstract}
OBJECTIVE Malignant meningioma is rare and classified as Grade III in the WHO classification of CNS tumors. However, the presence of estrogen receptor (ER) in WHO Grade III meningiomas and its correlation with patients' outcomes are still unclear. In this single-center cohort study, the authors analyzed clinical features, treatment, and prognosis of these malignant tumors in patients with long-term follow-up.
\end{abstract}

METHODS A total of 87 patients who were pathologically diagnosed with WHO Grade III meningiomas between 2003 and 2008 were enrolled in this study and followed for at least 7 years. Clinical information was collected to analyze the factors determining the prognosis.

RESULTS Twelve patients with rhabdoid, 12 with papillary, and 63 with anaplastic meningioma were included. The mean progression-free survival (PFS) and overall survival (OS) were $56.2 \pm 49.8$ months and $68.7 \pm 47.4$ months, respectively. No significant differences were observed among the 3 histological subtypes in either PFS $(p=0.929)$ or OS $(p=0.688)$. Patients who received gross-total resection had a longer PFS $(p=0.001)$ and OS $(p=0.027)$ than those who received subtotal resection. Adjuvant radiotherapy was associated with OS $(p=0.034)$ but not PFS $(p=0.433)$. Compared with primary meningiomas, patients with recurrent disease had worse PFS $(p<0.001)$. For patients who had malignant transformations, the prognosis was poorer than for patients without malignant transformations for both PFS $(p=0.002)$ and OS $(p=0.019)$. ER-positive patients had a significantly worse prognosis than ER-negative patients regarding both PFS ( $p=0.003)$ and OS $(p<0.001)$, whereas no association between progesterone receptor and patients' outcomes was observed. Multivariate analysis demonstrated that ER expression was an independent prognostic factor for both PFS $(p=0.008)$ and OS $(p<0.001)$.

CONCLUSIONS This retrospective study showed that patients with meningioma with ER-positive expression had a much worse prognosis than those with ER weak-positive or ER-negative status. The results demonstrated that ER is an independent prognostic factor for both PFS and OS of patients with WHO Grade III meningioma. The authors also found that more radical resection of the tumor, as well as postoperative radiotherapy, may prolong patients' survival time.

https://thejns.org/doi/abs/10.3171/2017.2.JNS162566

KEY WORDS malignant meningioma; prognosis; estrogen receptor; progesterone receptor; radiotherapy; oncology

$\mathrm{M}$ ENINGIOMA is one of the most common primary neoplasms in the CNS, constituting for approximately $36.4 \%$ of all intracranial tumors. ${ }^{27}$ Although most of them are benign and associated with a satisfying outcome, a small subset of meningiomas have more aggressive biological behaviors and are more likely to relapse. These malignant meningiomas were classified as Grade III in the WHO classification of CNS tumors. ${ }^{21}$ Three subtypes (anaplastic, rhabdoid, and papillary meningioma) account for $1 \%-3 \%$ of all meningioma grades. ${ }^{27,35}$

ABBREVIATIONS EMA = epithelial membrane antigen; ER = estrogen receptor; GTR = gross-total resection; KPS = Karnofsky Performance Scale; OS = overall survival; $\mathrm{PFS}=$ progression-free survival; $\mathrm{PR}=$ progesterone receptor; $\mathrm{STR}=$ subtotal resection; Vim = vimentin.

SUBMITTED October 18, 2016. ACCEPTED February 15, 2017.

INCLUDE WHEN CITING Published online August 18, 2017; DOI: 10.3171/2017.2.JNS162566.

${ }^{*}$ Drs. Hua and Zhu contributed equally to this work. 
WHO Grade III meningiomas have a male predominance and occur at much younger ages than WHO Grade I meningiomas. These tumors are characterized as having rapid growth, brain invasion, and nuclear atypia with a 5-year survival rate of $28 \%-61 \%$. ${ }^{6,10,18,24,31,34}$ Resection followed by postoperative radiotherapy is the first-line treatment of choice; no chemotherapy has ever been proven effective.

Estrogen and progesterone receptors have been reported to play a role in meningioma; some clinical trials targeting estrogen and progesterone receptors have also been conducted. ${ }^{13,15}$ The importance of estrogen and progesterone receptors in the prognosis of patients with meningioma has been investigated in some studies, but their roles in WHO Grade III meningiomas are still undetermined.,11,29

At Huashan Hospital in Shanghai, to our knowledge we enrolled the largest number of patients with WHO Grade III meningiomas in a long-term follow-up study to analyze clinical characteristics and predictive factors for prognosis.

\section{Methods \\ Patient Population}

A total of 4286 meningioma cases were surgically treated at the Department of Neurosurgery, Huashan Hospital, Shanghai, China, between 2003 and 2008. Among them, 12 rhabdoid, 15 papillary, and 70 anaplastic meningiomas were diagnosed. All surgical specimens were checked and confirmed by 2 experienced neuropathologists according to the $2007 \mathrm{WHO}$ grading system. Medical records were reviewed to collect clinical information. Follow-up was conducted either through the outpatient department or by telephone call, and all available pre- and postoperative CT/MR images were collected and analyzed. The extent of resection was evaluated according to the Simpson grading scale (gross-total resection [GTR], Simpson Grades I and II; and subtotal resection [STR], Simpson Grades III-V), using surgical records as well as postoperative MR images.

Seven patients with anaplastic and 3 patients with papillary meningiomas were lost to follow-up and excluded from analysis. Tumor location, presenting symptoms, preand postoperative Karnofsky Performance Scale (KPS) scores, Ki-67 labeling index, and related clinical information of the remaining 87 patients were collected and analyzed. This study was approved by the institutional review board of Huashan Hospital, Fudan University, and written informed consent was obtained from all patients.

\section{Immunohistochemical Analysis}

Immunohistochemical staining was performed using monoclonal antibodies to epithelial membrane antigens (EMAs), vimentin (Vim), estrogen receptor (ER), and progesterone receptor (PR) (Signalway Antibody; 1:200 dilution). The tumor was considered ER or PR positive if $>$ $10 \%$ of tumor cell nuclei showed staining; weak positive was established for 1\%-9\% of tumor cell nuclei stained; and tumors with no nuclei staining were regarded as negative. ${ }^{5}$ Three fields of each sample were viewed, and all counting results were repeated 3 times to calculate the mean value.

\section{Statistical Analysis}

Statistical analysis was performed using Stata 13 for Windows. Clinical data such as medians were summarized with descriptive analysis. Correlations between ER and PR expression were analyzed by linear regression. Categorical variables were compared with the Pearson $\chi^{2}$ test, and continuous variables were compared with the independent samples Student t-test (data with normal distribution) or the Mann-Whitney U-test (data with skewed distribution). Survival curves were generated using the Kaplan-Meier method, and the Cox proportional hazards test was used to analyze the prognostic factors. Data were considered statistically significant when $\mathrm{p}<0.05$.

\section{Results}

\section{Basic Data}

A total of 87 patients were enrolled in our series; patient characteristics and tumor locations are listed in Table 1. Among the lesions that the patients harbored, 12 were rhabdoid, 12 were papillary, and 63 were anaplastic meningiomas. Forty-seven patients were male (54\%) and 40 were female $(46 \%)$. The mean age at diagnosis was $47.7 \pm$ 15.3 years (range 6-79 years). No significant differences were observed for age $(\mathrm{p}=0.05)$ or sex $(\mathrm{p}=0.898)$ among the 3 histological subtypes. The presenting symptoms were mainly due to the tumor location. The median preoperative KPS score was 80 (range 20-100). The tumors were located mostly at the convexity $(n=40)$, followed by the parasagittal sinus $(n=13)$, tentorium $(n=9)$, sphenoid wing $(\mathrm{n}=8)$, lateral ventricle $(\mathrm{n}=5)$, anterior skull base $(n=4)$, spinal cord $(n=3)$, cerebellopontine angle $(n=2)$, middle cranial fossa $(n=1)$, jugular foramen $(n=1)$, and epidural space $(\mathrm{n}=1)$. In our series, a total of 28 patients (32.2\%) had a history of meningioma resection. Among them, 1 patient had received 3 previous meningioma resections, 5 patients had 2 previous resections, and the remaining 22 patients had received 1 previous resection. One patient with primary rhabdoid meningioma had a history of Gamma Knife surgery but no tumor resection.

\section{Surgical Procedure}

A total of 87 operations were performed. Simpson Grade I resection was achieved in 49 patients, Grade II resection in 18 patients; Grade III in 6 patients, and Grade IV in 13 patients; 1 patient underwent a biopsy for a suprasellar meningioma. Thus, 67 patients (77\%) had a GTR and 20 patients (23\%) had an STR. Convexity meningioma was more likely to have a Simpson Grade I resection than skull base meningioma $(\mathrm{p}=0.008)$. No patient died within 30 days of the operation. One patient required placement of a ventriculoperitoneal shunt 1 month after the tumor resection to treat postoperative hydrocephalus.

\section{Radiotherapy and Chemotherapy}

A total of 47 patients received postoperative radiotherapy in different forms 2-4 weeks after the initial surgery. Among them, 42 patients received traditional externalbeam radiotherapy in 2 daily fractions with $1-$ to $2-\mathrm{cm}$ clinical target volume and 3- to 5-mm planning target 
TABLE 1. Clinical characteristics, treatment, and prognosis of 87 patients with WHO Grade III meningiomas

\begin{tabular}{|c|c|}
\hline Characteristic & Value \\
\hline \multicolumn{2}{|l|}{ Histopathological results } \\
\hline Anaplastic & $63(72.4)$ \\
\hline Rhabdoid & $12(13.8)$ \\
\hline Papillary & $12(13.8)$ \\
\hline \multicolumn{2}{|l|}{ Sex } \\
\hline Male & $47(54.0)$ \\
\hline Female & $40(46.0)$ \\
\hline Age, yrs & $47.70 \pm 15.26$ \\
\hline \multicolumn{2}{|l|}{ Presenting symptoms } \\
\hline Headache & $34(39.1)$ \\
\hline Contralat weakness & $17(19.5)$ \\
\hline Motor seizure & $16(18.4)$ \\
\hline Visual disturbance & $8(9.2)$ \\
\hline Cognitive decline & $4(4.6)$ \\
\hline Aphasia & $2(2.3)$ \\
\hline Memory difficulties & $1(1.1)$ \\
\hline No symptoms & $8(9.2)$ \\
\hline \multicolumn{2}{|l|}{ Location } \\
\hline Convexity & $40(46.0)$ \\
\hline Parasagittal & $13(14.9)$ \\
\hline Tentorium & $9(10.3)$ \\
\hline Sphenoid wing & $8(9.2)$ \\
\hline Lateral ventricle & $5(5.7)$ \\
\hline Anterior skull base & $4(4.6)$ \\
\hline Spinal & $3(3.4)$ \\
\hline Cerebellopontine angle & $2(2.3)$ \\
\hline Middle fossa floor & $1(1.1)$ \\
\hline Jugular foramen & $1(1.1)$ \\
\hline Epidural & $1(1.1)$ \\
\hline Preop KPS score & 80 (range 20-100) \\
\hline Ki-67 labeling index, median & $10.8 \%$ (range $0 \%-70 \%$ ) \\
\hline Malignant transformation & $16(18.4)$ \\
\hline Grade I to III & $6(6.9)$ \\
\hline Grade II to III & $10(11.5)$ \\
\hline \multicolumn{2}{|l|}{ Primary vs recurrent } \\
\hline Primary & $59(67.8)$ \\
\hline Recurrent & $28(32.2)$ \\
\hline Follow-up, mos & $68.7 \pm 47.4$ (range $1-160)$ \\
\hline \multicolumn{2}{|l|}{ Extent of resection } \\
\hline GTR & $67(77.0)$ \\
\hline Simpson I & $49(56.3)$ \\
\hline Simpson II & $18(20.7)$ \\
\hline STR & $20(23.0)$ \\
\hline Simpson III & $6(6.9)$ \\
\hline Simpson IV & $13(14.9)$ \\
\hline Simpson V & $1(1.1)$ \\
\hline
\end{tabular}

CONTINUED IN NEXT COLUMN »
» CONTINUED FROM PREVIOUS COLUMN

TABLE 1. Clinical characteristics, treatment, and prognosis of 87 patients with WHO Grade III meningiomas

\begin{tabular}{|c|c|}
\hline Characteristic & Value \\
\hline Postop adjuvant therapy & $48(55.2)$ \\
\hline Radiotherapy & $34(39.1)$ \\
\hline Radiotherapy \& chemotherapy & $13(14.9)$ \\
\hline Chemotherapy & $1(1.2)$ \\
\hline \multicolumn{2}{|l|}{ PFS } \\
\hline Mean mos & $56.17 \pm 49.83$ \\
\hline 3 -yr rate & $52.9 \%$ \\
\hline 5-yr rate & $41.4 \%$ \\
\hline 7-yr rate & $37.9 \%$ \\
\hline \multicolumn{2}{|l|}{ OS } \\
\hline Mean mos & $68.66 \pm 47.41$ \\
\hline 3 -yr rate & $62.1 \%$ \\
\hline 5 -yr rate & $55.2 \%$ \\
\hline 7-yr rate & $49.4 \%$ \\
\hline \multicolumn{2}{|l|}{ Outcome at last follow-up } \\
\hline Deceased & $46(52.9)$ \\
\hline Died as the result of tumor recurrence & 43 \\
\hline Died due to other reasons & 3 \\
\hline Alive \& well & 32 \\
\hline Recurrence & 52 \\
\hline Alive w/ tumor progression & 9 \\
\hline Op after tumor recurrence & 14 \\
\hline \multicolumn{2}{|l|}{ ER expression } \\
\hline Positive & $36(41.4)$ \\
\hline Weak positive & $18(20.7)$ \\
\hline Negative & $33(38.0)$ \\
\hline \multicolumn{2}{|l|}{ PR expression } \\
\hline Positive & $7(8.0)$ \\
\hline Weak positive & $6(6.9)$ \\
\hline Negative & 74 (85.1) \\
\hline
\end{tabular}

Values are reported as no. (\%) unless otherwise indicated; means are presented \pm SD.

volume (mean dose $48.9 \pm 5.1$ Gy, range $32-66 \mathrm{~Gy}$ ); 4 patients received Gamma Knife surgery with a prescription dose of $14.0 \mathrm{~Gy}$ at the $50 \%$ isodose line $(28.0 \mathrm{~Gy}$ at the $100 \%$ isodose line); and 1 patient received CyberKnife treatment with $44 \mathrm{~Gy}$ in 5 fractions. Thirteen patients received concomitant chemotherapy (nimustine, semustine, or temozolomide) within 1 month after the operation. One patient received temozolomide chemotherapy only without radiotherapy. No patient received agents such as hydroxycarbamide or somatostatin. The remaining 39 patients did not receive any postoperative adjuvant therapy (neither radiotherapy nor chemotherapy).

\section{Immunohistochemical Analysis}

Histology examination revealed frequent necrosis, nuclear atypia, loss of cell architecture, and increased cellularity. Brain or bone invasion was observed in 30 patients (34.5\%). Immunohistochemical assays for EMA, Vim, 
Ki-67, ER, and PR were performed. The levels of immunoreactivity were classified into 3 categories: negative, weak positive, and positive. EMA and Vim were positive in all 87 cases. The mean Ki-67 labeling index was 10.5\% (range 0\%-70\%). ER was negative in $37.93 \%$ (33 of 87 patients), weak positive in $20.69 \%$ (18 of 87 patients), and positive in $41.38 \%$ ( 36 of 87 patients). PR was negative in $85.06 \%$ (74 of 87 patients), weak positive in $6.90 \%$ (6 of 87 patients), and positive in $8.05 \%$ (7 of 87 patients) (Table 1). No correlation was found between ER and PR expression $(p=0.730, r=0.001)$. In addition, no significant differences in ER $(p=0.090)$ and PR $(p=0.613)$ expression levels were observed among the 3 histological subtypes.

\section{Malignant Transformation}

Malignant transformation was defined as when a patient with WHO Grade III meningioma had a history of pathologically diagnosed WHO Grade I or II meningioma. Of 28 patients who were diagnosed with recurrent meningioma on admission, $16(57.1 \%)$ of them had a history of lower-grade meningioma surgery and were regarded as representative of cases of malignant transformation. Among these lesions, 6 were atypical, 8 were meningothelial, and 2 were fibrous. The median time for Grade II meningioma progression to Grade III was 49.5 months (range 13-72 months), whereas that from Grade I to III was 32.3 months (range 7-60 months). The progression time from Grades I and II to Grade III was not statistically significant $(\mathrm{p}=0.128)$.

\section{Outcome and Survival Analysis}

The date of the last follow-up was May 2016 through either the outpatient department or by telephone; postoperative T1-weighted contrast-enhanced MR images were also collected. The mean follow-up duration was 68.7 \pm 47.4 months (range 1-160 months). Forty-six patients $(52.9 \%)$ had died as of the last follow-up. The median KPS score at the last follow-up was 0 (range 0-100). A total of 55 patients had a deterioration of neurological status, and the extent of resection had no relationship with the improvement or worsening of neurological status ( $p$ $=0.487$ ).

The mean OS was $68.66 \pm 47.41$ months (range 1-160 months), with 3-, 5-, and 7-year OS rates of $62.1 \%, 55.2 \%$, and $49.4 \%$, respectively. The mean PFS was $56.17 \pm 49.83$ months (range 1-160 months), with 3-, 5-, and 7-year PFS rates of $52.9 \%, 41.4 \%$, and $37.9 \%$, respectively (Table 1 ).

There were no significant differences among the 3 histological subtypes in either PFS $(p=0.929)$ or OS $(p=$ 0.688) (Fig. 1A). Compared with skull base meningioma, patients with non-skull base meningioma had significantly longer PFS $(p=0.006)$ and OS $(p=0.043)$ (Fig. 1B). We further divided patients into 2 groups according to preoperative KPS score $(<80$ vs $\geq 80)$ and found that it was not a prognostic factor for either OS $(\mathrm{p}=0.987)$ or PFS $(\mathrm{p}=0.877)$. Patients who received GTR had significantly longer PFS $(p=0.001)$ and OS $(p=0.027)$ than those who received STR (Fig. 1C). Similar results were also found for postoperative radiotherapy. The OS $(\mathrm{p}=0.034)$ of patients who had postoperative radiotherapy was statistically longer than for those who did not, but in terms of PFS ( $p$ $=0.433)$ the difference was not significant (Fig. 1D). Postoperative chemotherapy was associated with shorter PFS $(\mathrm{p}=0.014)$ and OS $(\mathrm{p}=0.026)$, but did not show statistical significance as an independent prognostic factor after adjusting for covariates. Compared with primary meningiomas, recurrent cases had worse PFS $(\mathrm{p}=0.0001)$, but the OS between the groups was not significantly different $(\mathrm{p}=$ 0.107) (Fig. 2A). For patients who had malignant transformations, the prognosis was worse than for patients without malignant transformations regarding both PFS $(p=0.002)$ and OS (p = 0.019) (Fig. 2B).

\section{ER Was an Independent Prognostic Factor for PFS and OS}

We further divided patients into 3 groups according to the expression of ER. ER-negative, ER weak-positive, and ER-positive groups were identified according to the immunostaining expression level of ER. Neither ER ( $p=$ $0.339)$ nor PR $(p=0.505)$ was associated with change in neurological status. Survival analysis revealed that there were significant differences among these 3 subgroups. The outcomes of ER-positive patients were the worst, whereas among ER-negative patients, both PFS $(\mathrm{p}=0.003)$ and OS $(p<0.001)$ were the longest (Fig. 3A). Regarding PR expression, no statistical differences were observed among the PR-positive, PR weak-positive, and PR-negative subgroups regarding both PFS $(\mathrm{p}=0.526)$ and $\mathrm{OS}(\mathrm{p}=0.495)$ (Fig. 3B).

Factors such as age, sex, preoperative KPS score, tumor location, postoperative radiotherapy, chemotherapy, ER expression, PR expression, and recurrence status were included for multivariate survival analysis (Table 2). Multivariate analysis revealed that recurrence status $(\mathrm{p}=0.009)$ and ER expression $(\mathrm{p}=0.008)$ were independent prognostic factors for PFS, whereas for OS, only ER expression ( $p$ $=0.000$ ) was an independent factor.

\section{Discussion}

Although high-grade meningiomas are quite rare compared with WHO Grade I meningiomas, this subset of tumors bears totally different biological behavior and prognosis than WHO Grade I meningiomas. Most published studies combine WHO Grades II and III meningiomas for clinical or prognosis analysis. Studies that focus only on WHO Grade III meningiomas are very rare. With a deeper understanding of the cell biology of high-grade meningiomas, it is accepted that WHO Grade III meningiomas are different than Grade II meningiomas. ${ }^{1,9}$

In this study, we focused on WHO Grade III meningiomas. All enrolled patients underwent at least 1 resection in our department. To investigate the long-term outcome of Grade III meningiomas, we only included patients who underwent operations between 2003 and 2008; all patients had follow-up of at least 7 years. The 87 cases in our series are relatively representative, with anaplastic meningioma being the most common subtype.

Compared with other lower-grade meningiomas, it is more difficult to achieve radical resection for Grade III meningiomas, ${ }^{34}$ especially for those located on the skull base, with brain invasion, with sinus invasion, or tightly 


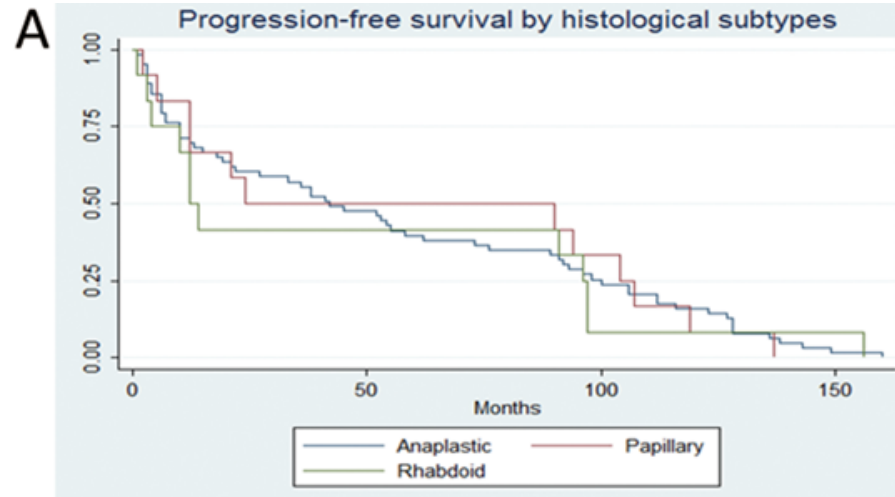

B

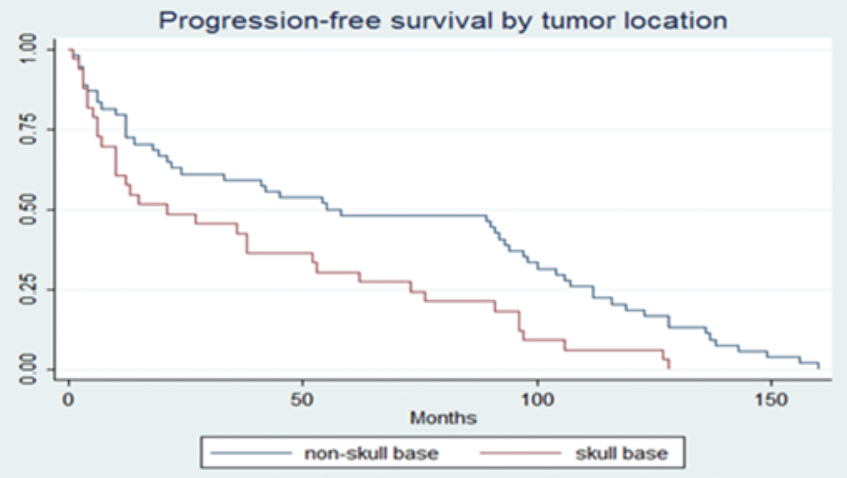

C

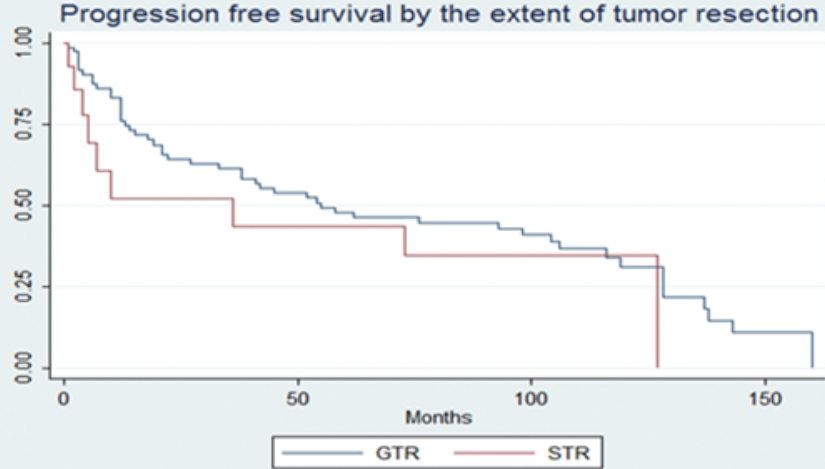

D

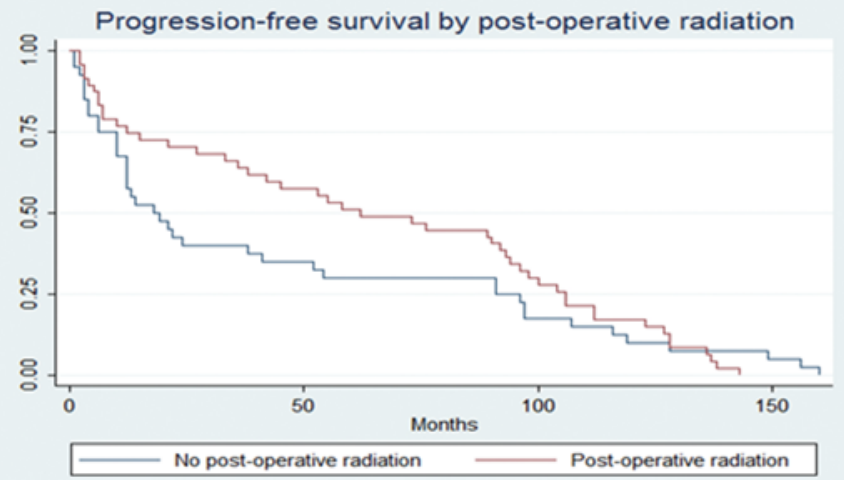

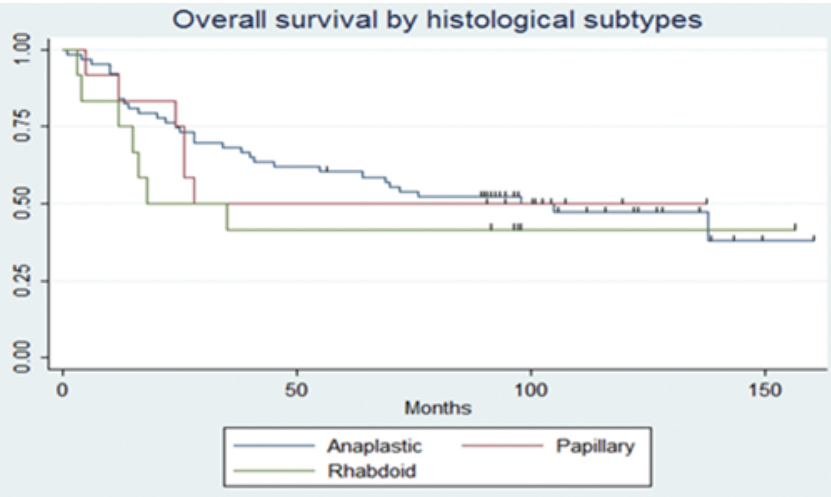

Overall survival by tumor location

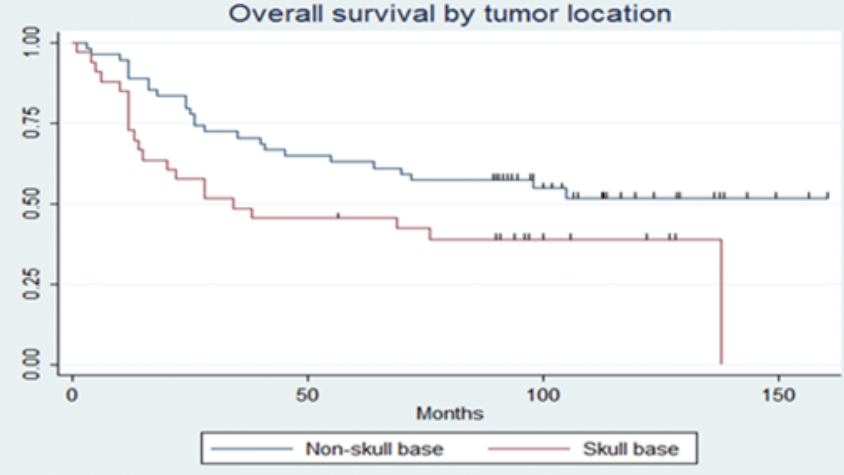

Overall survival by the extent of tumor resection

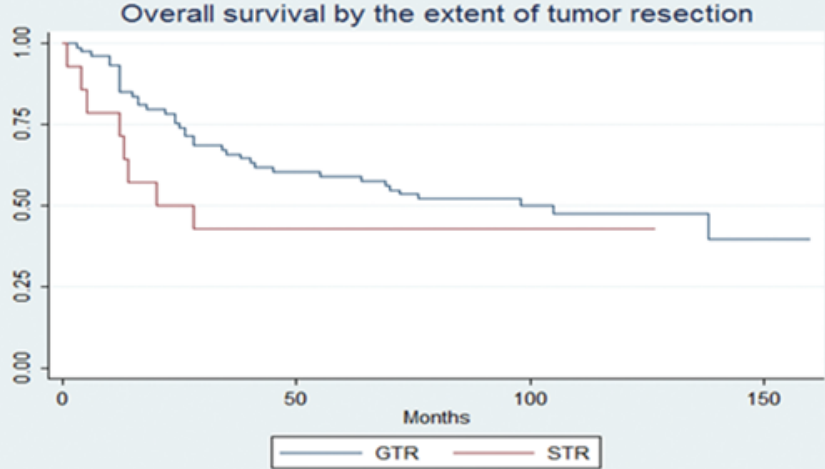

Overall survival by post-operative radiotherapy

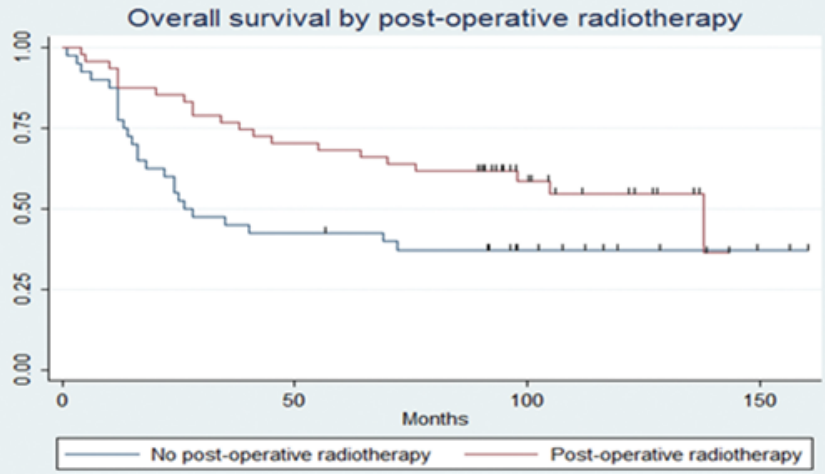

FIG. 1. Kaplan-Meier survival curves. A: PFS and OS of patients by histological subtypes. B: PFS and OS of patients by tumor location. C: PFS and OS of patients by the extent of tumor resection. D: PFS and OS of patients by absence or presence of postoperative radiotherapy.

wrapped around the main artery? In our series, the tumor location had a significant impact on the extent of tumor resection. GTR was more likely to be achieved for convex- ity meningiomas. There is still controversy on whether the extent of tumor resection has an effect on the outcome. ${ }^{16} \mathrm{In}$ the report by Sughrue et al. of 34 patients with malignant 

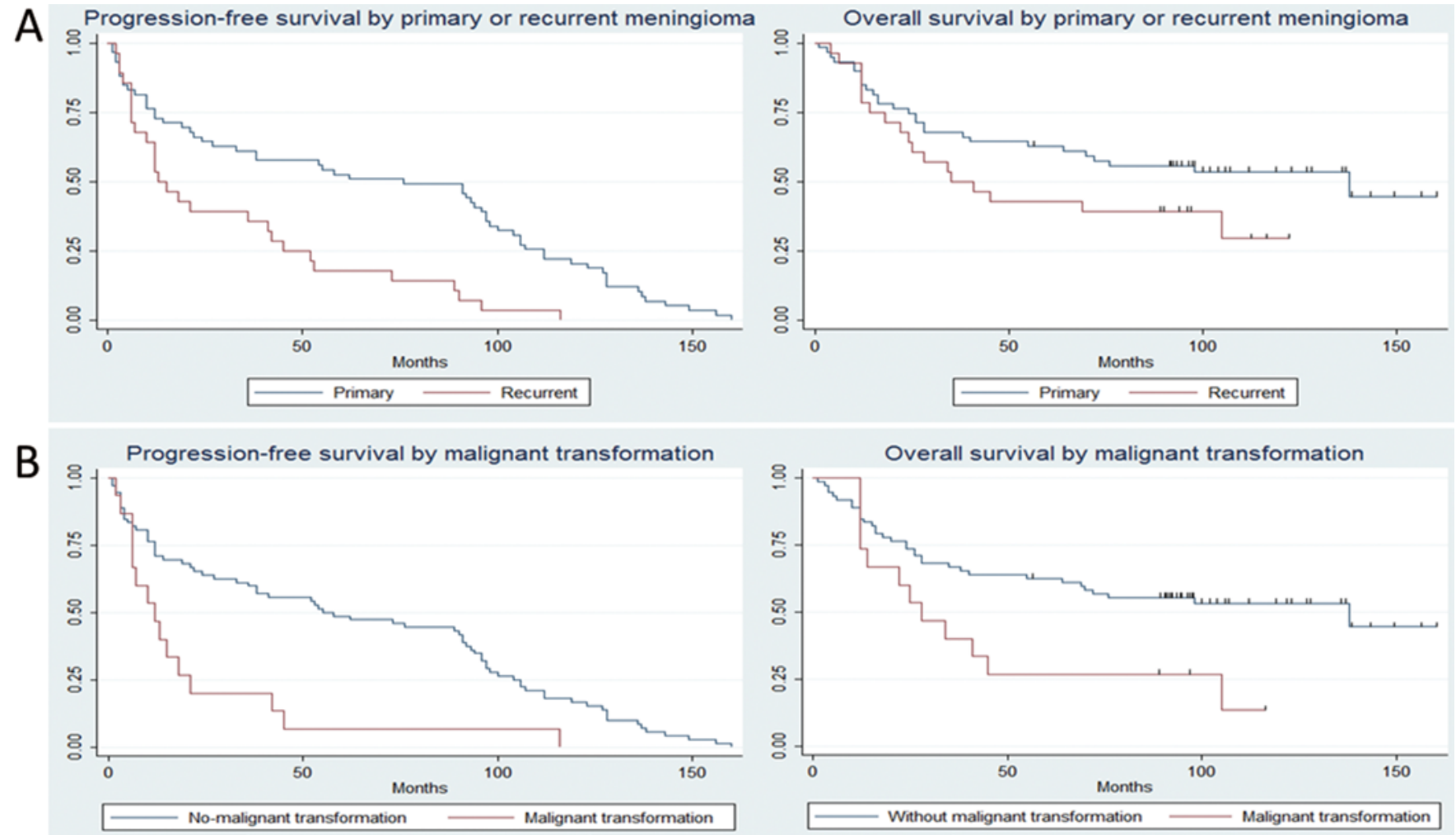

FIG. 2. Kaplan-Meier survival curves. A: PFS and OS of patients by primary or recurrent meningioma. B: PFS and OS of patients by absence or presence of malignant transformation.
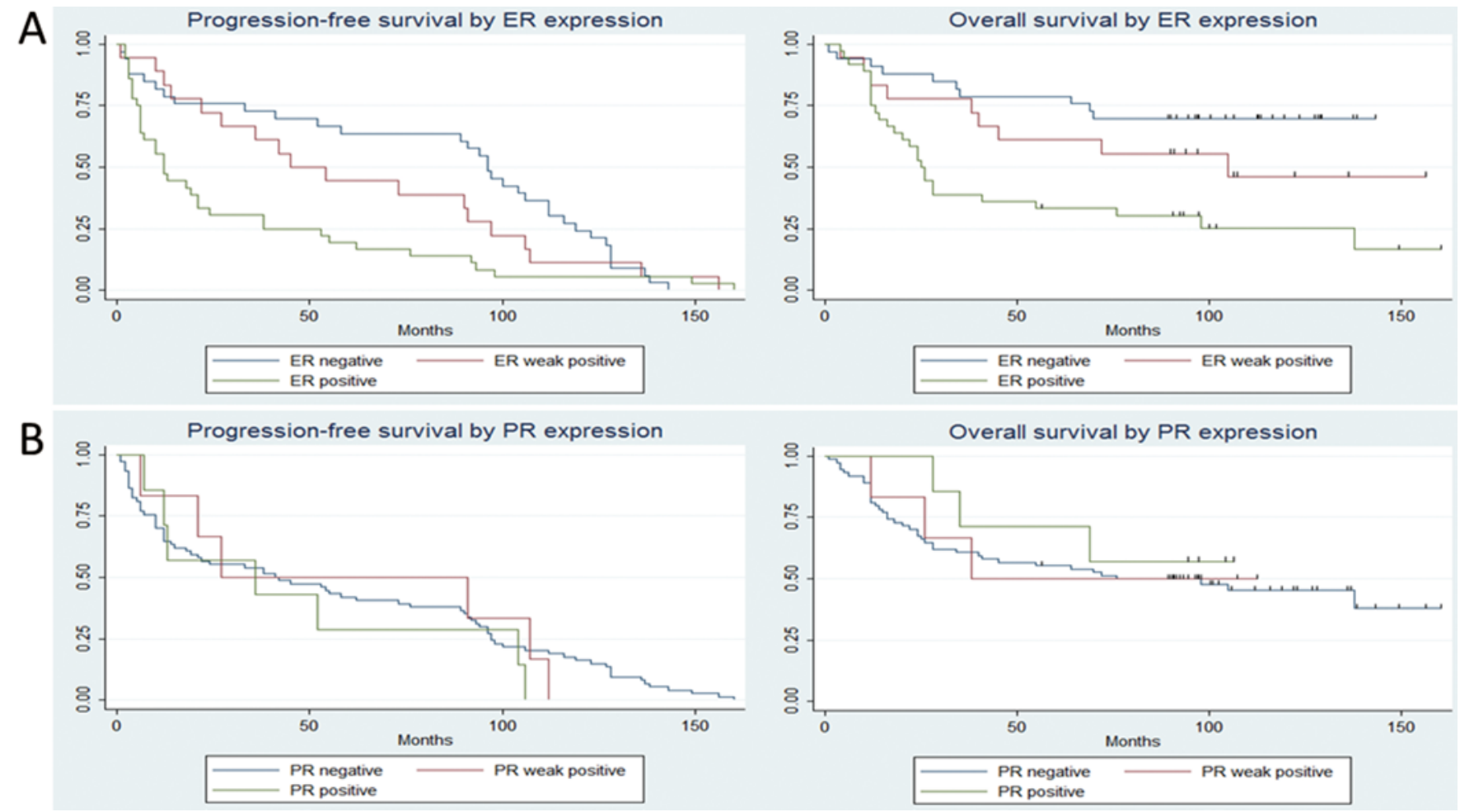

FIG. 3. Kaplan-Meier survival curves. A: PFS and OS of patients by ER expression. B: PFS and OS of patients by PR expression. 
TABLE 2. Univariate and multivariate analyses of prognostic factors in patients with WHO Grade III meningiomas

\begin{tabular}{|c|c|c|c|c|c|c|c|c|}
\hline \multirow[b]{3}{*}{ Variable } & \multicolumn{4}{|c|}{ Univariate Analysis } & \multicolumn{4}{|c|}{ Multivariate Analysis } \\
\hline & \multicolumn{2}{|r|}{ PFS } & \multicolumn{2}{|r|}{ OS } & \multicolumn{2}{|r|}{ PFS } & \multicolumn{2}{|r|}{ OS } \\
\hline & $\begin{array}{c}p \\
\text { Value }\end{array}$ & $\begin{array}{c}\mathrm{HR} \\
(95 \% \mathrm{Cl})\end{array}$ & $\begin{array}{c}p \\
\text { Value }\end{array}$ & $\begin{array}{c}\mathrm{HR} \\
(95 \% \mathrm{Cl})\end{array}$ & $\begin{array}{c}p \\
\text { Value }\end{array}$ & $\begin{array}{c}\mathrm{HR} \\
(95 \% \mathrm{Cl})\end{array}$ & $\begin{array}{c}p \\
\text { Value }\end{array}$ & $\begin{array}{c}\mathrm{HR} \\
(95 \% \mathrm{Cl})\end{array}$ \\
\hline Age (<60/ $\geq 60$ yrs $)$ & 0.819 & $1.062(0.636-1.733)$ & 0.974 & $1.012(0.502-2.039)$ & & & & \\
\hline Sex (female/male) & 0.669 & $0.911(0.593-1399)$ & 0.275 & $1.388(0.252-0.921)$ & & & & \\
\hline $\begin{array}{c}\text { Preop KPS score } \\
(<80 / \geq 80)\end{array}$ & 0.877 & $0.958(0.555-1.654)$ & 0.987 & $1.005(0.540-1.870)$ & & & & \\
\hline $\begin{array}{l}\text { Extent of resection } \\
\text { (GTR/STR) }\end{array}$ & $0.001^{*}$ & $0.412(0.246-0.692)$ & $0.027^{*}$ & $0.481(0.252-0.921)$ & & & & \\
\hline $\begin{array}{c}\text { Location (skull base/ } \\
\text { non-skull base) }\end{array}$ & $0.006^{*}$ & $1.887(1.195-2.978)$ & $0.043^{*}$ & $1.824(1.018-3.269)$ & & & & \\
\hline Radiotherapy (no/yes) & 0.433 & $0.841(0.544-1.298)$ & $0.034^{*}$ & $0.532(0.297-0.953)$ & & & & \\
\hline Chemotherapy (no/yes) & $0.014^{*}$ & $2.348(1.185-4.650)$ & $0.026^{*}$ & $2.177(1.099-4.315)$ & & & & \\
\hline Ki-67 index $(<5 \% / \geq 5 \%)$ & 0.958 & $0.988(0.621-1.570)$ & 0.847 & $1.064(0.567-1.995)$ & & & & \\
\hline ER & $0.003^{*}$ & $1.472(1.143-1.896)$ & $0.000^{*}$ & $1.958(1.364-2.809)$ & $0.008^{*}$ & $1.515(1.115-2.058)$ & $0.000^{*}$ & 1.958 (1.364-2.809) \\
\hline PR & 0.526 & $1.128(0.778-1.633)$ & 0.495 & $0.830(0.486-1.418)$ & & & & \\
\hline Recurrent (no/yes) & $0.000^{*}$ & $2.532(1.539-4.167)$ & 0.107 & $1.637(0.899-2.981)$ & $0.009^{*}$ & $2.185(1.215-3.929)$ & & \\
\hline
\end{tabular}

${ }^{*} p<0.05$ considered statistically significant.

meningioma, GTR was achieved in 23 patients and STR in 11, and the median survival of GTR-treated patients was statistically significant compared with STR-treated patients. ${ }^{34}$

However, in a study by Adeberg et al. concerning the long-term outcome of high-grade meningioma, the extent of resection did not affect the outcome of malignant meningioma. ${ }^{1}$ Durand et al. revealed similar results from their study of 33 patients with Grade III meningioma; the extent of resection affected neither OS nor PFS, ${ }^{9}$ whereas in our series of 87 patients with Grade III meningiomas, the extent of tumor resection was correlated with both PFS and OS (that is, more radical resection resulted in longer PFS and OS).

Postoperative radiation therapy has been widely accepted as an adjuvant therapy, especially for STR-treated patients. ${ }^{1,12,22,33,37}$ Both Durand et al. and Zhao et al. found that postoperative radiation therapy was significantly correlated with longer PFS or OS..$^{9,36}$ In our series, postoperative radiation treatment was associated with longer PFS and OS in WHO Grade III meningiomas, which is consistent with the published results. Because no clinical trial was conducted to decipher which type of radiotherapy is the best option for the management of Grade III meningioma, different surgeons have their own preferences. Currently, external-beam radiotherapy, Gamma Knife surgery, and CyberKnife therapy are all applied in patients with meningioma. Further studies are needed to evaluate the best dose, time, and subtype of radiotherapy.

Chemotherapy for meningioma is usually a salvage therapy for recurrent or unresectable meningiomas. Although various clinical trials concerning meningioma have been conducted, few reported having a benefit. ${ }^{25} \mathrm{Cur}-$ rently, only 2 drugs, interferon alpha and somatostatin analogs, are recommended for the treatment of meningioma by the National Comprehensive Cancer Network. In our series, only 14 patients received a short course of nonstandard chemotherapy; none of them used the recommended drug. Although the results from analysis showed that postoperative chemotherapy had a poor influence on both PFS and OS, multivariate analysis failed to show that it is an independent prognostic factor. It is hard to conclude that postoperative chemotherapy does harm to patients. Furthermore, the small number of patients in the series as well as irregular use of various drugs made it hard to draw the conclusion that postoperative chemotherapy is ineffective or harmful for the management of WHO Grade III meningiomas. Because patients who underwent chemotherapy were those who did not receive radical tumor resections, there is a possibility that the effect of STR masked the role of chemotherapy. The effect of chemotherapy and standard chemotherapy schemes for treatment of malignant meningiomas need to be further explored.

Meningioma has a sex predominance. In benign meningiomas, females are more likely to be affected, whereas in high-grade meningiomas males are more likely to be affected..$^{27,35}$ Various studies have reported an acceleration in growth of meningioma during pregnancy or in postmenopausal patients who received exogenous hormone therapy. $3,4,8,23,28,30$ Evidence shows that hormones play a role in meningioma development. Chemotherapy targeting ER, PR, and SSTR2a has been studied in clinical trials in multiple centers. ${ }^{13-15,26}$

Leães et al. enrolled a total of 126 patients with meningioma as well as 19 normal control subjects for analysis of ER expression; they found that ER was present in $24.6 \%$ of patients with meningioma and in $0 \%$ of controls. ${ }^{20} \mathrm{Hsu}$ et al. reported that in their series of 70 patients, ER expression was only positive in 6 patients (8.6\%). ${ }^{17}$ Barresi et al. reported that in their series of 58 patients with spinal meningioma, ER expression was not found in any patients. ${ }^{2}$ Fakhrjou et al. investigated the effect of ER expression on 
prognosis in their series of 50 patients; ER is seldom expressed in meningioma, but its presence signified a good prognosis, which did not correlate with our results. ${ }^{11}$

Pravdenkova et al. investigated the effects of ER and PR on prognosis, showing results similar to ours. Among their 239 meningioma cases, PR signaled a favorable clinical and biological outcome, whereas ER was correlated with an accumulation of qualitative and quantitative karyotype abnormalities; a higher proportion of involvement of chromosomes 14 and 22 in de novo tumors; and an increased potential for aggressive clinical behavior, progression, and recurrence of meningioma, ${ }^{29}$ which partly correlated with our results.

Roser et al. investigated the prognostic value of PR in their series of 588 patients with meningioma..$^{32}$ They concluded that PR is expressed more in Grade I meningioma and together with the proliferation index, PR status can help to predict recurrence, which is partly consistent with the study reported by Pravdenkova et al. However, Iplikcioglu et al. reported that PR was not a prognostic factor in their series of 48 patients, which contained all 3 grades. ${ }^{19}$ Clinical trials targeting ER and PR have been conducted in a number of centers. Published results have not been satisfying. ${ }^{13,15}$ However, existing clinical trials did not separate receptor-positive and -negative patients. Thus, it is possible that these drugs are only effective in receptorpositive patients.

We analyzed the relationship between ER and PR expression and the OS in Grade III meningiomas for the first time, to our knowledge, and revealed that ER expression was significantly associated with patients' outcomes. In our series, ER expression was an independent prognostic factor for both PFS and OS. The density of ER immunostaining was associated with the prognosis, whereas PR failed to show values for predicting the prognosis. However, because PR expression was only positive in $8 \%$ of patients in our series, it is hard to draw the conclusion that PR has no value for predicting prognosis in patients with Grade III meningiomas. More patients must be enrolled to analyze the value of PR. The molecular mechanisms underlying the phenomenon were also unclear and need further exploration.

In this study, we only reported ER and PR expression in Grade III meningiomas. The status of ER and PR, as well as their values in predicting prognosis in lower-grade meningiomas, need to be elucidated to draw the landscape of ER and PR expression in all subtypes of meningioma.

\section{Conclusions}

ER is a valuable factor in determining the prognosis of WHO Grade III meningiomas. The density of ER expression is greatly associated with prognosis. In addition, multivariate analysis showed that ER is an independent prognostic factor for both PFS and OS, whereas similar results were not shown for PR.

\section{Acknowledgments}

This study was supported by grants from the National Natural Science Foundation of China (no. 81372707 to Y. Gong) and the Science and Technology Commission of Shanghai Municipality (no. 16140903000 to Y. Gong and no. 15140902200 to H. Tang).

\section{References}

1. Adeberg S, Hartmann C, Welzel T, Rieken S, Habermehl D, von Deimling A, et al: Long-term outcome after radiotherapy in patients with atypical and malignant meningiomas-clinical results in 85 patients treated in a single institution leading to optimized guidelines for early radiation therapy. Int J Radiat Oncol Biol Phys 83:859-864, 2012

2. Barresi V, Alafaci C, Caffo M, Barresi G, Tuccari G: Clinicopathological characteristics, hormone receptor status and matrix metallo-proteinase-9 (MMP-9) immunohistochemical expression in spinal meningiomas. Pathol Res Pract 208:350-355, 2012

3. Baxter DS, Smith P, Stewart K, Murphy M: Clear cell meningioma presenting as rapidly deteriorating visual field and acuity during pregnancy. J Clin Neurosci 16:1502-1504, 2009

4. Benson VS, Kirichek O, Beral V, Green J: Menopausal hormone therapy and central nervous system tumor risk: large UK prospective study and meta-analysis. Int J Cancer 136:2369-2377, 2015

5. Blankenstein MA, Berns PM, Blaauw G, Mulder E, Thijssen $\mathrm{JH}$ : Search for estrogen receptors in human meningioma tissue sections with a monoclonal antibody against the human estrogen receptor. Cancer Res 46 (8 Suppl):4268s-4270s, 1986

6. Boskos C, Feuvret L, Noel G, Habrand JL, Pommier P, Alapetite $\mathrm{C}$, et al: Combined proton and photon conformal radiotherapy for intracranial atypical and malignant meningioma. Int J Radiat Oncol Biol Phys 75:399-406, 2009

7. Champeaux C, Wilson E, Brandner S, Shieff C, Thorne L: World Health Organization Grade III meningiomas. A retrospective study for outcome and prognostic factors assessment. Br J Neurosurg 29:693-698, 2015

8. Claus EB, Calvocoressi L, Bondy ML, Wrensch M, Wiemels JL, Schildkraut JM: Exogenous hormone use, reproductive factors, and risk of intracranial meningioma in females. $\mathbf{J}$ Neurosurg 118:649-656, 2013

9. Durand A, Labrousse F, Jouvet A, Bauchet L, Kalamaridès M, Menei P, et al: WHO Grade II and III meningiomas: a study of prognostic factors. J Neurooncol 95:367-375, 2009

10. Dziuk TW, Woo S, Butler EB, Thornby J, Grossman R, Dennis WS, et al: Malignant meningioma: an indication for initial aggressive surgery and adjuvant radiotherapy. J Neurooncol 37:177-188, 1998

11. Fakhrjou A, Meshkini A, Shadrvan S: Status of Ki-67, estrogen and progesterone receptors in various subtypes of intracranial meningiomas. Pak J Biol Sci 15:530-535, 2012

12. Ferraro DJ, Funk RK, Blackett JW, Ju MR, DeWees TA, Chicoine MR, et al: A retrospective analysis of survival and prognostic factors after stereotactic radiosurgery for aggressive meningiomas. Radiat Oncol 9:38, 2014

13. Goodwin JW, Crowley J, Eyre HJ, Stafford B, Jaeckle KA, Townsend JJ: A Phase II evaluation of tamoxifen in unresectable or refractory meningiomas: a Southwest Oncology Group study. J Neurooncol 15:75-77, 1993

14. Graillon T, Defilles C, Mohamed A, Lisbonis C, Germanetti AL, Chinot O, et al: Combined treatment by octreotide and everolimus: octreotide enhances inhibitory effect of everolimus in aggressive meningiomas. J Neurooncol 124:33-43, 2015

15. Grunberg SM, Weiss MH, Russell CA, Spitz IM, Ahmadi $\mathrm{J}$, Sadun A, et al: Long-term administration of mifepristone (RU486): clinical tolerance during extended treatment of meningioma. Cancer Invest 24:727-733, 2006

16. Hanft S, Canoll P, Bruce JN: A review of malignant meningiomas: diagnosis, characteristics, and treatment. J Neurooncol 99:433-443, 2010

17. Hsu DW, Efird JT, Hedley-Whyte ET: Progesterone and estrogen receptors in meningiomas: prognostic considerations. J Neurosurg 86:113-120, 1997 
18. Hug EB, Devries A, Thornton AF, Munzenride JE, Pardo FS, Hedley-Whyte ET, et al: Management of atypical and malignant meningiomas: role of high-dose, 3D-conformal radiation therapy. J Neurooncol 48:151-160, 2000

19. Iplikcioglu AC, Hatiboglu MA, Ozek E, Ozcan D: Is progesteron receptor status really a prognostic factor for intracranial meningiomas? Clin Neurol Neurosurg 124:119-122, 2014

20. Leães CG, Meurer RT, Coutinho LB, Ferreira NP, PereiraLima JF, da Costa Oliveira M: Immunohistochemical expression of aromatase and estrogen, androgen and progesterone receptors in normal and neoplastic human meningeal cells. Neuropathology 30:44-49, 2010

21. Louis DN, Ohgaki H, Wiestler OD, Cavenee WK, Burger PC, Jouvet A, et al: The 2007 WHO classification of tumours of the central nervous system. Acta Neuropathol 114:97-109, 2007

22. Marcus HJ, Price SJ, Wilby M, Santarius T, Kirollos RW: Radiotherapy as an adjuvant in the management of intracranial meningiomas: are we practising evidence-based medicine? Br J Neurosurg 22:520-528, 2008

23. Michaud DS, Gallo V, Schlehofer B, Tjønneland A, Olsen A, Overvad K, et al: Reproductive factors and exogenous hormone use in relation to risk of glioma and meningioma in a large European cohort study. Cancer Epidemiol Biomarkers Prev 19:2562-2569, 2010

24. Milosevic MF, Frost PJ, Laperriere NJ, Wong CS, Simpson WJ: Radiotherapy for atypical or malignant intracranial meningioma. Int J Radiat Oncol Biol Phys 34:817-822, 1996

25. Moazzam AA, Wagle N, Zada G: Recent developments in chemotherapy for meningiomas: a review. Neurosurg Focus 35(6):E18, 2013

26. Norden AD, Ligon KL, Hammond SN, Muzikansky A, Reardon DA, Kaley TJ, et al: Phase II study of monthly pasireotide LAR (SOM230C) for recurrent or progressive meningioma. Neurology 84:280-286, 2015

27. Ostrom QT, Gittleman H, Fulop J, Liu M, Blanda R, Kromer $\mathrm{C}$, et al: CBTRUS statistical report: primary brain and central nervous system tumors diagnosed in the United States in 2008-2012. Neuro Oncol 17 (Suppl 4):iv1-iv62, 2015

28. Pikis S, Cohen JE, Rosenthal G, Barzilay Y, Kaplan L, Shoshan Y, et al: Spinal meningioma becoming symptomatic in the third trimester of pregnancy. J Clin Neurosci 20:1797-1799, 2013

29. Pravdenkova S, Al-Mefty O, Sawyer J, Husain M: Progesterone and estrogen receptors: opposing prognostic indicators in meningiomas. J Neurosurg 105:163-173, 2006

30. Rodríguez-Porcel F, Hughes I, Anderson D, Lee J, Biller J: Foster Kennedy syndrome due to meningioma growth during pregnancy. Front Neurol 4:183, 2013
31. Rosenberg LA, Prayson RA, Lee J, Reddy C, Chao ST, Barnett GH, et al: Long-term experience with World Health Organization Grade III (malignant) meningiomas at a single institution. Int J Radiat Oncol Biol Phys 74:427-432, 2009

32. Roser F, Nakamura M, Bellinzona M, Rosahl SK, Ostertag $\mathrm{H}$, Samii M: The prognostic value of progesterone receptor status in meningiomas. J Clin Pathol 57:1033-1037, 2004

33. Simon M, Boström J, Koch P, Schramm J: Interinstitutional variance of postoperative radiotherapy and follow up for meningiomas in Germany: impact of changes of the WHO classification. J Neurol Neurosurg Psychiatry 77:767-773, 2006

34. Sughrue ME, Sanai N, Shangari G, Parsa AT, Berger MS, McDermott MW: Outcome and survival following primary and repeat surgery for World Health Organization Grade III meningiomas. J Neurosurg 113:202-209, 2010

35. Wang DJ, Xie Q, Gong Y, Mao Y, Wang Y, Cheng HX, et al: Histopathological classification and location of consecutively operated meningiomas at a single institution in China from 2001 to 2010. Chin Med J (Engl) 126:488-493, 2013

36. Zhao P, Hu M, Zhao M, Ren X, Jiang Z: Prognostic factors for patients with atypical or malignant meningiomas treated at a single center. Neurosurg Rev 38:101-107, 2015

37. Zhu H, Xie Q, Zhou Y, Chen H, Mao Y, Zhong P, et al: Analysis of prognostic factors and treatment of anaplastic meningioma in China. J Clin Neurosci 22:690-695, 2015

\section{Disclosures}

The authors report no conflict of interest concerning the materials or methods used in this study or the findings specified in this paper.

\section{Author Contributions}

Conception and design: Gong, Hua, Zhu, Xie. Acquisition of data: Hua, Zhu, Li, H Tang, Kuang. Analysis and interpretation of data: Hua, Zhu. Drafting the article: Hua. Critically revising the article: Xie. Reviewed submitted version of manuscript: Gong, Hua, Zhu, Xie. Approved the final version of the manuscript on behalf of all authors: Gong. Statistical analysis: Hua, Zhu. Administrative/technical/material support: Wang, F Tang. Study supervision: Gong, Chen, Zhou, Xie.

\section{Correspondence}

Ye Gong, Departments of Neurosurgery and Critical Care Medicine, Huashan Hospital, Shanghai Medical College, Fudan University, 12 Middle Wulumuqi Rd., Jingan District, Shanghai 200040, China. email: drgongye@163.com. 